\title{
Evolution of Nanoparticles in the Gas Phase during the Floating Chemical Vapor Deposition Synthesis of Carbon Nanotubes
}

\author{
Yiguo $\mathrm{Xu}^{1}$, Yang $\mathrm{Ma}^{2}$, Yu Liu ${ }^{1}$, Shan Feng ${ }^{1}$, Delong $\mathrm{He}^{1}$ Paul Haghi-Ashtiani ${ }^{1}$, \\ Anthony Dichiara ${ }^{3}$, Laurent Zimmer ${ }^{4}$, and Jinbo Bai ${ }^{1}$ \\ ${ }^{1}$ Laboratoire MSSMat,CNRS UMR 8579, CentraleSupélec,Université Paris-Saclay, 8-10 rue Joliot-Curie, \\ 91190, Gif-sur-Yvette, France \\ ${ }^{2}$ Key Laboratory of Aerospace Advanced Materials and Performance of Ministry of Education, School of \\ Materials Science and Engineering, Beihang University, 100191 Beijing, China \\ ${ }^{3}$ School of Environmental and Forest Sciences (SEFS), University of Washington, 4000 15th Avenue NE, \\ Seattle, Washington 98195, United States \\ ${ }^{4}$ Laboratoire EM2C, CNRS-CentraleSupélec-Université Paris Saclay, France
}

Corresponding author : E-mail: delong.he@ecp.fr - jinbo.bai@ecp.fr

Preprint submitted to The Journal of Chemistry Physics C

\section{Graphical abstract}

The evolution of nanoparticles (NPs) in the gas phase during the floating chemical vapor deposition synthesis of carbon nanotubes (CNTs) was investigated. NPs were detected in the gas phase along the reactor axis, and their nature and size were characterized by highresolution transmission electron microscopy equipped with energy-dispersive spectroscopy analysis. Their roles during the CNTs growth were also discussed by correlating the information about the morphology of the CNTs synthesized on the substrate along the reactor axis. It is found that iron NPs form and grow quickly in the front of the reactor at a temperature above $750{ }^{\circ} \mathrm{C}$, whereas the NP growth finally terminate when they are encapsulated by the carbon layers during the downstream region of the reactor. Because of the carbon encapsulation, iron NPs could not directly contribute to the CNT growth on the substrate.
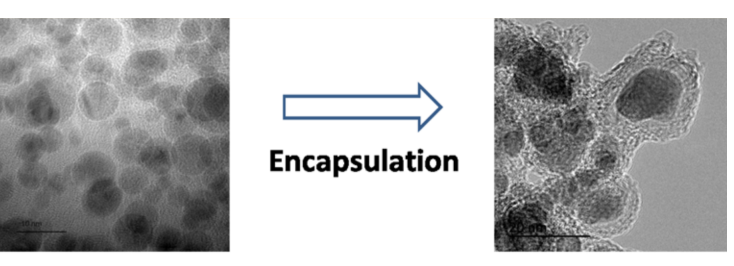
Carbon-encapsulated iron NPs

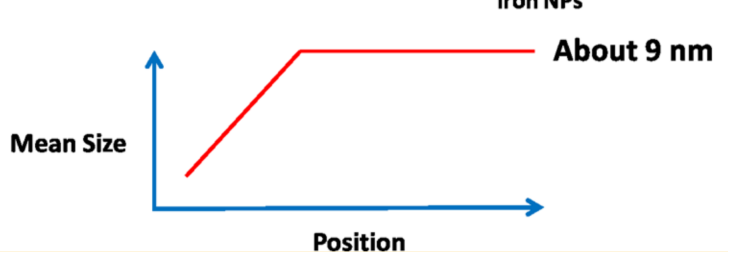
These results demonstrate that homogeneous nucleation is not the prerequisite for the CNT growth on the substrate 


\section{Introduction}

Carbon nanotubes (CNTs) have been extensively investigated catalytic NP formation process during FCCVD is desired for large-scale production. In the last decades for their outstanding properties and a wide range of potential applications, such as electronics [1,2], photonics [3], energy storage [4,5], water and air purification [6,7] and structural composites [8,9]. Among the different synthesis methods, floating catalytic chemical vapor deposition (FCCVD) is widely used for large-scale production of CNTs. The growth of CNTs by FCCVD is distinguished from other chemical vapor deposition (CVD) processes by simultaneous injection of hydrocarbon and catalytic precursors into the reactor [10,11]. Ferrocene is one of the most commonly used catalytic precursors because of its good stability, low cost, and nontoxicity [12]. The carbon sources are methane, acetylene, benzene, and xylene [13-16]. It has been believed that the thermal decomposition of ferrocene leads to the nucleation of iron particles, where the decomposed carbon can diffuse, precipitate, and assemble into tubular structures. The diameter of CNTs is directly proportional to the size of the catalyst particles $[17,18]$, and the length of CNTs is also affected by the catalyst morphology and activity [19]. Therefore, controlling the size and the morphology of the iron catalytic nanoparticles (NPs) is critical for synthesizing large amount of CNTs with well-defined structures and properties [20,21]. However, it remains an unsolved challenge. Therefore, a quantitative understanding of the catalytic NP formation process during FCCVD is desired for large-scale production.

Most studies focus on the final products of iron catalytic NPs on the substrate, relying on ex-situ post-experimental characterization techniques [22-25]. However, it is difficult to trace these catalysts evolution. Thus, the evolution of iron catalytic NPs has been seldomly addressed in the FCCVD process. Because the catalytic NPs originate from the decomposition of ferrocene in the gas phase, homogeneous nucleation is proposed as one possible mechanism for the iron NP formation. Moisala et al. demonstrated that the thermal decomposition of ferrocene will result in the formation of supersaturated metal vapor in the reactor, enabling nucleation and growth of iron NPs via condensation and coagulation in the gas phase due to the very low iron saturated vapor pressure [26]. Castro et al. found that the change in iron vapor pressure has a great influence on the CNT growth efficiency and diameter. They further deduced that homogeneous nucleation is the dominant mechanism for the iron-based particle formation in the gas phase [27]. Zhang et al. successfully modulated the diameter of CNTs by controlling the concentration of the iron atom at the initial rate. It reinforced the homogeneous nucleation hypothesis of iron NPs in the gas phase [28]. Castro et al. also found that the strong correlation between the size and the number density of NPs can be well explained by the homogeneous nucleation hypothesis, which further underlined the importance of controlling the homogeneous nucleation of catalytic particles [29]. On the basis of the homogeneous nucleation hypothesis, the formation process and the growth rate of NPs from thermal decomposition of ferrocene were simulated by computational fluid dynamics (CFD) methods [?]. These simulation results explained the experimental observations that the diameter of the iron NPs increases with the increase in the temperature and the ferrocene concentration. However, the above-mentioned results are based on speculations or indirect evidences. Direct experiments are desired for clarifying the formation mechanism of iron catalytic NPs. Furthermore, CFD simulations predicted that the size of catalytic iron NPs will increase along the reactor axis, whereas the results in the study on the position-dependent growth of the multi-walled CNT on alumina microparticle contradict this prediction [33]. In addition, the NPs are considered as pure iron in all the CFD models. Nevertheless, the NP nature in the gas phase is still in doubt.

Thus, this work is devoted to investigate the evolution of iron-based NPs in the gas phase during the CNT synthesis by the CVD method. For this purpose, NPs were detected in the gas phase along the CVD reactor. Their nature and evolution as a function of the position and CVD condition were systematically characterized by high-resolution transmission electron microscopy (HRTEM) equipped with energy- dispersive spectroscopy analysis. By correlating the information on the morphology of the CNT synthesis on the substrate, the roles of NPs in the gas phase during the CNT growth were discussed. 


\section{Experimental section}

\subsection{CVD Process and NP Collection.}

The scheme of the CVD system was described in our previous studies [33-35]. To collect the NPs at different positions along the CVD reactor, a special stainless steel reactor (120 cm in length and $45 \mathrm{~mm}$ in diameter) was designed, which had seven small open-ended tubes $(15 \mathrm{~cm}$ in length and $6.3 \mathrm{~mm}$ in diameter) installed at different positions labeled P1, P2, P3, P4, P5, P6, and P7 along the reactor, as depicted in Figure 1. In each CVD run, P5 was positioned in the center of the furnace. CNTs were synthesized on two different substrates: quartz plates and microspherical alumina particles $\left[\mu-\mathrm{Al}_{2} \mathrm{O}_{3}, 3-10 \mu \mathrm{m}\right.$ in diameter, purchased from Performance Ceramic Company (Peninsula, OH, USA)]. When microspherical alumina particles $\mu-$ $\mathrm{Al}_{2} \mathrm{O}_{3}$ were used as the substrate, they were homogeneously dispersed on the surface of the quartz plate, which was put into the center of the furnace. Then, the furnace was heated up by an electrical resistance furnace (CARBOLITE) to a high temperature (from 650 to $850^{\circ} \mathrm{C}$ ) under an argon/hydrogen atmosphere. After $20 \mathrm{~min}$, the precursor solution consisted of a liquid feedstock of carbon source xylene (Alfa Aesar) with dissolved ferrocene (from 0.01 to $0.1 \mathrm{~g} / \mathrm{mL}$ ) was injected at $0.2 \mathrm{~mL} / \mathrm{min}$ in the form of spray. Acetylene was also provided to the system at a rate of $0.02 \mathrm{~L} / \mathrm{min}$ to accelerate the synthesis of CNTs [36, 37]. Here, the injection of liquid xylene and the gases was controlled by a syringe system fitted with a liquid flow meter (Razel Science, R99-E) and by digital mass flow meters (Bronkhorst), respectively. The total gas flow rate was kept to $1 \mathrm{~L} / \mathrm{min}$ during the whole process. After $6 \mathrm{~min}$ solution injection, the transmission electron microscopy (TEM) samples were collected at different positions along the reactor axis. A thorough statistical analysis of over 50 NPs or tubes was conducted for each synthesis condition. The results were subjected to one-way analysis of variance. Statistical differences in diameter were determined with p-values smaller than 0.05. To elucidate the roles of NPs during the CNT growth, CNTs synthesized on quartz plates and alumina particles were collected at the same CVD condition.

\subsection{Characterization}

TEM was performed using a FEI Titan instrument equipped with an aberration-corrected condenser operating at $200 \mathrm{kV}$. Scanning electron microscopy (SEM) was conducted on a FEI Quanta 200 SEM instrument with an accelerating voltage of $5 \mathrm{kV}$. Raman spectra were recorded over the range of 1000-2000 $\mathrm{cm}^{-1} \mathrm{with}^{\mathrm{a}}$ spectral resolution of $1 \mathrm{~cm}^{-1}$ by a Jobin Yvon LabRam spectrometer using the $632.8 \mathrm{~nm}$ emission of a HeNe laser source. Thermogravimetric analyses (TGAs) were conducted using a Netzsch analyzer (STA449F3 Jupiter) from 50 to $900^{\circ} \mathrm{C}$ at a heating rate of $10^{\circ} \mathrm{C} / \mathrm{min}$ under an oxidizing atmosphere (flow rate of the mixture of $\mathrm{N}_{2}$ and $\mathrm{O}_{2}, 20 \mathrm{~mL} / \mathrm{min}: 20 \mathrm{~mL} / \mathrm{min}$ ).

\section{Results and discussion}

The evolution of NPs along the reactor axis was investigated by TEM at $850^{\circ} \mathrm{C}$ with $0.2 \mathrm{~mL} / \mathrm{min}$ ferrocene dissolved into xylene at $0.05 \mathrm{~g} / \mathrm{mL}$ under $0.78 \mathrm{~L} / \mathrm{min}$ argon, $0.2 \mathrm{~L} / \mathrm{min}_{2}$, and $0.02 \mathrm{~L} / \mathrm{min}_{2} \mathrm{H}_{2}$ atmosphere. We successfully detected NPs in the gas phase from P2 to P7, whereas at P1, we did not observe any NPs at all, which indicated that NPs did not form at P1 in the gas phase. The typical TEM images of NPs obtained in the gas phase at different positions (from P2 to P7) are shown in Figure 2a-f, respectively.

In the TEM images, the spherical particles of 4-15 $\mathrm{nm}$ in size are found. In addition, particle agglomerates are observed. In Figure 2g, the high-resolution TEM image of NPs at the center of the heated zone (P5) is also presented. As observed, the NPs contain 3-10 graphite layers. In addition, they exhibit a core-shell structure with an iron core and a carbon shell. For many particles, lattice fringes of the core material are visible, showing that they are crystals (Figure $2 \mathrm{~h}$ ). Furthermore, selected-area electron diffraction patterns (EDPs) (Figure $2 \mathrm{~h}$ inset) were recorded to identify the crystal structure of the iron core. According to the EDP results, we can determine that the iron core is $\alpha$-Fe (ferrite, body-centered cubic, a $=0.287 \mathrm{~nm}$ ). 
Noteworthy, at the front of the reactor (P3), a large number of NPs exhibit another kind of structure, as depicted in Figure 2i. No obvious graphite shell or very thin layer of carbon around the iron core is found in these particles. These observations indicate that a large number of NPs display the structure change from iron NPs in the front of the heated zone (P2-P4) to carbon-encapsulated iron ones in the downstream region (P5-P7). In addition, the elemental analysis of NPs at the front (P3) and in the center of the heated zone (P5) by energy-dispersive X-ray (EDX) spectroscopy was carried out. At the front of the heated zone (P3), it can be seen that iron, carbon, oxygen, copper, and silicon elements are detected (Figure 3a).

The copper element results from the copper grid used for NP support. The silicon element is probably related to impurities from the quartz tube during sampling. The peaks around 0.6 and $6.4 \mathrm{keV}$ correspond to the iron element, which comes from the iron core of NPs. Owing to the TEM grid covered by the thin carbon layer for NP support, the presence of the carbon element peak in all samples is presumably related to the carbon cover on the copper TEM grid or the graphite layer around the iron core. The peaks around $0.5 \mathrm{keV}$ correspond to the oxygen element. The map of spatial distribution of iron, carbon, and oxygen elements in the sample is presented in Figure 3b-d, respectively. We can see a high concentration of iron element, which distribute in the center of NPs. It is interesting to note that oxygen elements are found in the NPs at P3, indicating that the surface of NPs is possibly oxidized. In our experiment, NPs are detected at the outlet of the tube. Inside the CVD reactor, iron NPs are protected from being oxidized in the argon atmosphere. Therefore, oxidation must take place at the outlet of the small tube. The spectrum of chemical elements and the map distribution of the elements in NPs at the center of the heated zone (P5) are presented in Figure 3e-g. We can find the presence of iron and carbon elements. In addition, there are always some carbon elements around the iron core at the suspended region in the sample. This is the direct evidence of the presence of the amount of carbon content in the NPs, which is in good agreement with the TEM image (Figure 2g).

The size evolution of NPs along the reactor axis was also investigated. Because the structure of NPs change from iron NPs to carbon-encapsulated iron NPs along the reactor axis, as discussed before, only the size distribution of the iron core is taken into account in the whole text. The size distribution of the iron core at different locations along the reactor is presented by the histogram in Figure 4.

The mean diameters of the iron NPs at positions P2, P3, P4, P5, P6, and P7 are 4.9, 6.3, 7.2, 9.1, 9.3, and $8.8 \mathrm{~nm}$, respectively. In the front of the reactor, the mean diameter of NPs is found to increase from $4.9 \mathrm{~nm}$ at P3 to $9.1 \mathrm{~nm}$ at P5 along the reactor. It reaches the maximum at P5. The bigger NPs are found closer to the center of the furnace. However, the NP size distribution does not show obvious difference from P5 to P7. It means that the size of NPs remain constant in the downstream region along the reactor. The formation process and the growth rate of NPs from thermal decomposition of ferrocene were predicted by CFD simulations in previous works [?]. In these models, the NP growth process in an argon atmosphere was described by the homogeneous nucleation theory. NPs formed by homogeneous nucleation and then grew up by coalescence. CFD simulations predicted that the NP size increased along the reactor. As observed in Figure 4, the NP size indeed increases from $4.9 \mathrm{~nm}$ at P1 to $9.1 \mathrm{~nm}$ at P5 in the front of the reactor, which is in good agreement with the prediction. However, the NP size distribution does not show obvious difference from $\mathrm{P} 5$ to $\mathrm{P} 7$, indicating that the termination of the NP growth occurs in the downstream region of the reactor. This phenomenon contra- dicts the CFD prediction. It is worth emphasizing that the NPs are assumed to be pure iron NPs and the effect of the carbon element on the iron NP growth is not taken into account in the CFD models, whereas the NPs at the center of the heated zone are not pure iron NPs but carbon-encapsulated iron ones. The iron core is always covered by the carbon layers, as observed in Figure 2g. According to the above discussions, we attribute the termination of the NP growth to the carbon encapsulation under the studied conditions. Iron atoms generate from the thermal decomposition of ferrocene. Once the iron partial pressure is higher than its saturated vapor pressure, iron NPs will form by homogeneous nucleation. Because the pyrolysis of hydrocarbon carbon does not take place at about $850^{\circ} \mathrm{C}[38]$ one can suppose that the carbon atoms generate by the catalytic decomposition of hydrocarbon on the iron NP surface. They dissolve into iron NP during the growth process, finally precipitate from the iron NP surface. As observed in Figure 4, the mean diameter size of NPs increases from P2 to P5, corresponding to the growth process of a large number of NPs. During the growth process, NPs are pure iron NPs or carbon and iron mixture. In addition, a large number of NPs have been encapsulated by the amount of carbon atoms at P5. The NP growth process will stop. Therefore, no obvious increase in the size is observed from P5 to P7. Furthermore, according to the EDX, the oxygen element is not found in the NPs at P5. These results indicate that iron NPs have already been encapsulated by the graphite layers inside the reactor at the center of the heated zone (P5). The graphite layer can effectively prevent NPs from 
being oxidized. Although in the front of the heated zone (P3), a large number of NPs are not completely covered by the carbon atoms, there are still some active iron atoms on the surfaces of the NPs. They will be oxidized in the oxygen environment. Therefore, we can find the presence of oxygen in the NPs at P3.

As discussed before, during the whole NP growth process, free carbon atoms or clusters generate by the catalytic decomposition of hydrocarbon on the iron NP surface, dissolve into NPs, and finally precipitate from the surface of NPs. Once iron NPs are encapsulated by the carbon layer, they stop growing up. Therefore, the final size of the iron-based NPs will depend on the competition between the rate of iron NP growth and carbon encapsulation. To investigate the effect of CVD conditions on the NP size, the size distribution of the iron core was examined at different experiment conditions, such as temperature, ferrocene concentration, $\mathrm{C}_{2} \mathrm{H}_{2}$ flow rate, and $\mathrm{H}_{2}$ flow rate. Because NPs at the center of the heated zone (P5) are already encapsulated by the carbon layer, in the following CVD runs, the NPs at P5 were collected by TEM. First, TEM was performed at 650,750 , and $850^{\circ} \mathrm{C}$. It is found that the temperature exhibits a pronounced effect on the NP formation in the gas phase. At $650^{\circ} \mathrm{C}$, no NPs are observed at all. It means that no iron, carbon, or binary iron-carbon NPs form by homogeneous nucleation in the gas phase below $650^{\circ} \mathrm{C}$. In contrast, NPs were successfully detected at 750 and $850^{\circ} \mathrm{C}$, the mean diameters of iron NPs in the gas phase at 750 and $850^{\circ} \mathrm{C}$ are 4.4 and $9.1 \mathrm{~nm}$, respectively, as seen in Figure 5a, indicating an obvious increase with the temperature increasing from 750 to $850^{\circ} \mathrm{C}$. At high temperature, the thermal decomposition of ferrocene will occur more quickly. It will result in the increase of the iron density per volume in the gas phase, hence facilitating homogeneous nucleation and growth of NPs in the gas phase, finally leading to larger NPs. For ferrocene concentration ranging from 0.01 to $0.05,0.1 \mathrm{~g} / \mathrm{L}$, the mean diameters of NPs are 3.5, 4.4, and 5.4 $\mathrm{nm}$, as depicted in Figure 5b.

The mean diameter of NPs increases with the increase of ferrocene concentration. The increase of the NP size can be attributed to the enhanced nucleation because of the higher iron concentration in the gas phase. High ferrocene concentration will result in a higher iron vapor pressure. It can promote the nucleation and coalescence of NPs in the gas phase. Figure 5c shows the NP size distributions at the $\mathrm{C}_{2} \mathrm{H}_{2}$ flow rate ranging from 0 to $0.08 \mathrm{~L} / \mathrm{min}$. As can be observed, the mean diameter of NPs is $5.8 \mathrm{~nm}$ when no $\mathrm{C}_{2} \mathrm{H}_{2}$ is injected. The mean diameter diminishes to $4.4 \mathrm{~nm}$ when $0.02 \mathrm{~L} / \mathrm{min} \mathrm{C} 2 \mathrm{H} 2$ is provided. Further increase in the $\mathrm{C} 2 \mathrm{H} 2$ flow rate will make the mean diameter decrease to $3.9 \mathrm{~nm}$ at a $\mathrm{C}_{2} \mathrm{H}_{2}$ flow rate of $0.08 \mathrm{~L} / \mathrm{min}$. It suggests that the carbon supply rate is enhanced at a higher $\mathrm{C}_{2} \mathrm{H}_{2}$ flow rate. More carbon atoms will accumulate on the catalyst surface, iron-based NPs will more easily be encapsulated before they grow up to larger ones. The NP size distributions at different $\mathrm{H} 2$ flow rates are demonstrated in Figure 5d. As can been seen, the mean diameters of NPs are 5.7, 4.4, and $5.1 \mathrm{~nm}$ with $\mathrm{H}_{2}$ flow rates of $0,0.2$, and $0.4 \mathrm{~L} / \mathrm{min}$, respectively. The mean diameter of NPs first increases with higher $\mathrm{H}_{2}$ up to 0.2 $\mathrm{L} / \mathrm{min}$, and also the size distribution is noticeably narrowed. When the $\mathrm{H}_{2}$ flow rate increases further to 0.4 $\mathrm{L} /$ min, the mean diameter of NPs increases to $5.1 \mathrm{~nm}$. It seems that $\mathrm{H} 2$ serves a dual role during the NP growth process in the gas phase. Therefore, the effect of $\mathrm{H}_{2}$ on the NP growth can be both facilitating and inhibiting depending on the amount of $\mathrm{H}_{2}$ in the CVD conditions. It can be interpreted by the homogeneous nucleation hypothesis. At relatively low $\mathrm{H}_{2}$ flow rate $(0.2 \mathrm{~L} / \mathrm{min})$, the replacement of $20 \% \mathrm{Ar}$ (molar mass: $40 \mathrm{~g} / \mathrm{mol}$ ) by a lighter gas $\mathrm{H}_{2}$ (molar mass: $2 \mathrm{~g} / \mathrm{mol}$ ) will change the nucleation rate though its influence on the collisions during the NP growth process in the gas phase. Because the energy exchange per collision is too small for too small molar masses [?] $\mathrm{H}_{2}$ addition $(0.2 \mathrm{~L} / \mathrm{min})$ will increase the nucleation rate, finally results in the reduction of the size of NPs. At higher flow rates $(0.4 \mathrm{~L} / \mathrm{min})$, the etching effect of $\mathrm{H}_{2}$ becomes dominate. $\mathrm{H} 2$ can react with carbon and reduces the carbon deposition rate on the surface of iron NPs [42]. Thus, the NP size increases with the increase of the $\mathrm{H}_{2}$ gas flow from 0.2 to $0.4 \mathrm{~L} / \mathrm{min}$.

To provide insight on the roles of NPs in the gas phase during the CNT growth, CNTs were also synthesized on the substrate. CVD was performed at $850^{\circ} \mathrm{C}$ with $0.2 \mathrm{~mL} / \mathrm{min}$ ferrocene dissolved into xylene at $0.05 \mathrm{~g} / \mathrm{mL}$ under $0.78 \mathrm{~L} / \mathrm{min} \mathrm{Ar}, 0.2 \mathrm{~L} / \mathrm{min} \mathrm{H}_{2}$, and $0.02 \mathrm{~L} / \mathrm{min}_{2} \mathrm{H}_{2}$ atmosphere. It was found that CNTs grew only in the front of the reactor (from P1 to P4) on the quartz plate; no CNTs were observed from P5 to P7. Figure 6a-d displays the typical morphology of the CNTs synthesized on the quartz plate in the reactor at different axial locations (from $\mathrm{P} 1$ to $\mathrm{P} 4$ ) at $950 \circ \mathrm{C}$. As observed, the start of the CNT growth on the quartz plate occurs at the location P1 along the reactor. However, the as-synthesized CNTs exhibit a poor degree of alignment, short lengths $(6 \mu \mathrm{m})$, and low density (Figure 6a).

From P2 to P4, the highly dense well- aligned CNTs synthesize on the quartz plate (Figure 6b-d). The 
obvious length change can be observed along the reactor. The length of CNTs at P2 increases to $24 \mu \mathrm{m}$ and then reaches its maximum of $42 \mu \mathrm{m}$ at P3. When it is closer to the center of the reactor, the lengths of the CNTs become shorter $(33 \mu \mathrm{m})$ at P4. However, from the center of the reactor (P5) to the rear (P7), no CNTs are observed on the quartz plate. Raman profiles of CNTs at different axial locations are presented in Figure 7a. All specimens display two first-order peaks near 1330 and $1590 \mathrm{~cm}^{-1}$, assigned to the D-bands and G-bands, respectively. The G-band is the characteristic peak for the stretching vibration of carbon sp2 bonds in a hexagonal lattice, and the D-band corresponds to the disordered sp2 phase plus possible contributions of the scattering of sp3-bonded carbon.43 The intensity ratio of the G-band to the D-band (IG/ID) is commonly invoked as a benchmark of the CNT crystallinity. Figure 7b is a plot of the IG/ID ratio of the CNTs at different locations. The IG/ID ratio first increases from 0.73 at P1, passing to 0.87 at $\mathrm{P} 2$ and to 1.05 at P3, where highly dense well-aligned CNTs with long length are observed. Finally, The IG/ID ratio decreases again to 0.99 at P4. Comparing Figure $7 \mathrm{~b}$ with Figure 6a-d, it can be found that the IG/ID ratio and the length of CNTs display the similar tendency. These results indicate that longer CNTs tend to present higher crystalline quality, which is consistent with other studies [44].

It should be noted that no NPs were detected at P1 in the gas phase, as described previously. However, CNTs were synthesized successfully at the same location on the substrate. It means that homogeneous nucleation is not the prerequisite for the CNT growth on the substrate. In addition, the TEM image of CNTs on the quartz plate at the front of the heated zone (P3) is presented in Figure 8. The typical structure of CNTs can be identified. The diameter of CNTs is about 20-40 nm.

The interesting observation is the presence of NPs decorated on the CNT wall. They are in size of about 4-15 nm, the sizes of which are similar to the NPs in the gas phase. It is reasonable to assume that these NPs nucleate in the gas phase. They attach to the CNT during the CNT growth process by the gas flow. It is also significant that the NP size detected in the gas phase is far from that measured on the substrate, revealing that NPs in the gas phase do not directly attach to the substrate for the CNT growth. It can be verified by the observation that the size of NPs in the gas phase increases quickly along the reactor axis from P2 to P5 and keeps constant from P5 to P7, whereas the NP evolution on the substrate does not exhibit the similar trend. If NPs in the gas phase can further participate in the CNT growth on the substrate, it must be believed that the NPs would coalesce on the substrate. However, as depicted in Figure 2g, iron NPs are encapsulated by the graphite layers. Because of the graphite layer, the carbon-encapsulated iron NPs are very stable, they cannot coalesce on the substrate to form large NPs for the CNT growth on the substrate. According to these discussions, it can be deduced that NPs in the gas phase cannot directly attach to the substrate for the CNT growth or aggregate on the substrate to larger catalytic NPs for the CNT growth once they are encapsulated by the graphite layers.

In addition, CNTs were also synthesized on $\mu-\mathrm{Al}_{2} \mathrm{O}_{3}$ at different temperatures. As can be observed in Figure $9 \mathrm{a}$, at $650^{\circ} \mathrm{C}$, the highly dense CNTs are found to be well-aligned and perpendicular to the $\mathrm{\mu}-\mathrm{Al}_{2} \mathrm{O}_{3}$ surface at the center of the heated zone (P5).

The average length of CNTs reaches up to $10-15 \mu \mathrm{m}$. When increasing the temperature to $750^{\circ} \mathrm{C}$, less CNTs are observed on the substrate. In addition, they exhibit a poor degree of alignment, short lengths, and low density (Figure 9b). At $850^{\circ} \mathrm{C}$, no CNT growth is observed on $\mathrm{\mu}-\mathrm{Al}_{2} \mathrm{O}_{3}$ (Figure 9c). Moreover, the yield of CNTs at the center of the heated zone (P5) measured by TGA exhibits a good correlation with observations in the SEM image, as shown in Figure 9d. The oxidation temperatures for the as-synthesized CNTs are in the range of $400-650^{\circ} \mathrm{C}$. The yield of CNTs declines from 24.4 to $6.8 \mathrm{wt} \%$ when the temperature increases from 650 to $750^{\circ} \mathrm{C}$. Further increase in the temperature to $850^{\circ} \mathrm{C}$, the yield drops to $2.1 \mathrm{wt} \%$. The output of CNTs on the substrate follows an opposite trend with the mean diameters of NPs in the gas phase. The poor alignment and low yield of CNTs on the substrate at high temperature can be explained as follows. At high temperature, more carbon-encapsulated iron NPs form in the gas phase, which will consume amount of iron atoms and carbon atoms. Because carbon-encapsulated iron NPs are not responsible for the CNT growth on the substrate, the effective iron and carbon are greatly reduced. Less iron will participate in the formation of catalytic iron NPs on the substrate, resulting in the poor alignment and low yield of CNTs on the substrate. It is also emphasized that NPs are not detected at any place in the gas phase at $650^{\circ} \mathrm{C}$. However, vertically aligned CNTs synthesize successfully on the substrate. It further confirms that homogeneous nucleation is not the prerequisite for the CNT growth on the substrate. Therefore, there must be another NP formation mechanism for the CNT growth on the substrate. 
According to the above results and discussions, we can deduce that there are two kinds of NP nucleation mechanisms in the FCCVD process (Figure 10). One kind of NP formation mechanism is homogeneous nucleation, which occurs directly in the gas phase. NPs formed by homogeneous nucleation are about 4-12 $\mathrm{nm}$. They always are encapsulated by carbon layers. Another kind of NP formation mechanism happens on the substrate by heterogeneous nucleation. NPs formed by heterogeneous nucleation are about 20-35 $\mathrm{nm}$, which are much larger than those in the gas phase at the same position along the reactor. They are utilized as the catalysts for the vertically aligned CNT growth on the substrate in the studied conditions. The different sizes of NPs in the gas phase and on the substrate can be explained by the thermodynamics of the NP nucleation.45 The relationship between the free-energy change to form NPs from the vapor by heterogeneous nucleation and by homogeneous nucleation can be described by the following equation

$$
G_{\text {hetero }}=\frac{1}{4}(1-\cos \theta)^{2}(2+\cos \theta) \cdot G_{\text {homo }}
$$

where $G_{\text {hetero }}$ is the energy needed for forming critical nucleus for heterogeneous nucleation. $G_{\text {homo }}$ is the energy needed for forming critical nucleus for homogeneous nucleation. $\theta$ is the contact angle between the critical nucleus and the substrate. According to eq $1, G_{\text {hetero }}<G_{\text {homo. The heterogeneous nucleation }}$ can lower the energy barrier. Therefore, the heterogeneous nucleation is easier than the homogeneous nucleation, which means the NPs have a higher opportunity to form on the substrate than in the gas phase. In previous studies, Lu et al. and Elliott et al. observed that the morphology of the CVD product strongly depends on the carbon feeding rate $[46,47]$. Therefore, in our CVD conditions, a supply of carbon in the initial feedstock with a $\mathrm{C} / \mathrm{Fe}$ molar ratio of 284 always lets the smaller iron NPs to be encapsulated in the gas phase but allows the larger NPs to be utilized as the catalysts for the CNT growth on the substrate.

As investigated previously, the morphology of the CVD product strongly relates with the carbon feeding rate [46]. Therefore, the $\mathrm{C} / \mathrm{Fe}$ molar ratio in the initial feedstock is expected to have a great influence on the NP morphology in the gas phase. To valid this speculation, TEM samples in the gas phase were collected at a low $\mathrm{C} / \mathrm{Fe}$ molar ratio and a high $\mathrm{C} / \mathrm{Fe}$ molar ratio. At a low $\mathrm{C} / \mathrm{Fe}$ molar of 132 , when no $\mathrm{C}_{2} \mathrm{H}_{2}$ was provided and the ferrocene concentration was fixed at $0.1 \mathrm{~g} / \mathrm{mL}$. The temperature of the furnace was set to $750^{\circ} \mathrm{C}$. Interestingly, CNTs directly grow in the gas phase, as shown in Figure 11a. The diameter of CNTs is about $11.5 \mathrm{~nm}$ (Figure 11b), comparable to the diameters of the iron NPs located at the tube ends, but larger than the diameters of the abundant carbon-encapsulated iron NPs. These lightweight CNTs are easily carried away with the gas flow and deposit at the end of the quartz tube. The results are in agreement with the previous observations.48,49 In contrast, the products were also collected on the quartz plate at a much higher $\mathrm{C} / \mathrm{Fe}$ molar ratio of 4356 . To avoid the effect of homogeneous nucleation in the gas phase, CVD was performed at $650^{\circ} \mathrm{C}$. A solution of $0.01 \mathrm{~g} / \mathrm{mL}$ ferrocene/xylene was injected into the reactor. Meanwhile, the injection of acetylene as the carbon source was performed at a flow rate $0.4 \mathrm{~L} / \mathrm{min}$. The $\mathrm{C} / \mathrm{Fe}$ molar ratio is about 4356. The SEM and TEM micrographs of collected power on the quartz substrate are shown in Figure 11c,d. As can be seen in Figure 11c, no vertically aligned CNTs were found in the collected powder. TEM results show that the collected powder consists of iron NPs, which are confined by carbon layers (Figure 11d). The diameter of iron NPs is about $8.1 \mathrm{~nm}$, which is much smaller than that of NPs on the substrate at lower $\mathrm{C} / \mathrm{Fe}$ molar ratio. It demonstrates that at a high $\mathrm{C} / \mathrm{Fe}$ molar ratio in the initial feedstock, iron NPs on the substrate will also be encapsulated by the carbon layers. These results confirm our speculation of the two kinds of iron-based NP nucleation mechanisms in the gas phase and on the substrate.

\section{Conclusions}

In summary, the evolution of iron-based NPs in the gas phase during CVD for the CNT synthesis was investigated. It was found that homogeneous nucleation really occurred in the gas phase at a temperature above $750^{\circ} \mathrm{C}$ under the conditions studied, and the size of NPs increased quickly at the front of the reactor due to the homogeneous nucleation and coalescence and kept a constant value during the downstream region in the reactor due to the carbon encapsulation. During the NP growth, carbon atoms are generated by the catalytic decomposition of hydrocarbon on the iron NP surface to form carbon layers, which prohibit the growth of NPs. The as- formed carbon-encapsulated iron NPs exhibit core-shell structures, with $\alpha$-Fe cores and graphitic shells. In addition, the CVD conditions, such as temperature, ferrocene concen- tration, $\mathrm{C} 2 \mathrm{H} 2$ 
gas flow, and H2 gas flow, have a great influence on the mean diameters of NPs. Because of the carbon encapsulation, iron NPs could not directly contribute to the CNT growth on the substrate. It is important to note that in some situations, no NPs formed in the gas phase, but CNTs were synthesized successfully at the same location on the substrate. For example, at $850^{\circ} \mathrm{C}$, no NPs were detected at location P1, whereas CNTs were observed at the same location on the quartz plate. Similar phenomenon also be observed at $650^{\circ} \mathrm{C}$. NPs did not nucleate in the gas phase, but highly dense CNTs also obtained on $\mu-\mathrm{Al}_{2} \mathrm{O}_{3}$. These results show that homogeneous nucleation in the gas phase is not the prerequisite for the CNT growth on the substrate. This research is helpful to achieve precise control of catalytic NP nucleation for the growth of CNTs in the FCCVD process.

\section{Acknowledgments}

This work was carried out within the MATMECA consortium and supported by the ANR under contract number ANR-10- EQPX-37. Y.X. gratefully acknowledges the support of a Ph.D. stipend from the Chinese Scholarship Council (CSC).

\section{ORCID-Id}

Delong He: 0000-0002-9947-6177

Laurent Zimmer: 0000-0002-6428-8520

Jinbo Bai: 0000-0002-6581-0157

\section{References}

[1] Sun, D.-m.; Timmermans, M. Y.; Tian, Y.; Nasibulin, A. G.; Kauppinen, E. I.; Kishimoto, S.; Mizutani, T.; Ohno, Y. Flexible high- performance carbon nanotube integrated circuits. Nat. Nanotechnol. 2011, $6,156-161$.

[2] Liang, Y.; Li, Y.; Wang, H.; Dai, H. Strongly coupled inorganic/ nanocarbon hybrid materials for advanced electrocatalysis. J. Am. Chem. Soc. 2013, 135, 2013-2036.

[3] Avouris, P.; Freitag, M.; Perebeinos, V. Carbon-nanotube photonics and optoelectronics. Nat. Photonics 2008, 2, 341-350.

[4] Jha, N.; Ramesh, P.; Bekyarova, E.; Tian, X.; Wang, F.; Itkis, M. E.; Haddon, R. C. Functionalized single-walled carbon nanotube-based fuel cell benchmarked against US DOE 2017 technical targets. Sci. Rep. 2013, 3, 2257.

[5] Dichiara, A. B.; Yuan, J.; Yao, S.; Sylvestre, A.; Zimmer, L.; Bai, J. Effective synergistic effect of $\mathrm{Al}_{2} \mathrm{O}_{3}$ and $\mathrm{SiC}$ microparticles on the growth of carbon nanotubes and their application in high dielectric permittivity polymer composites. J. Mater. Chem. A 2014, 2, 7980-7987.

[6] Nasibulin, A. G.; Kaskela, A.; Mustonen, K.; Anisimov, A. S.; Ruiz, V.; Kivistö, S.; Rackauskas, S.; Timmermans, M. Y.; Pudas, M.; Aitchison, B. Multifunctional free-standing single-walled carbon nanotube films. ACS Nano 2011, 5, 3214-3221.

[7] Tofighy, M. A.; Mohammadi, T. Salty water desalination using carbon nanotube sheets. Desalination 2010, 258, 182-186.

[8] Li, W.; Dichiara, A.; Bai, J. Carbon nanotube-graphene nanoplatelet hybrids as high-performance multifunctional reinforce- ments in epoxy composites. Compos. Sci. Technol. 2013, 74, 221-227. 
[9] Zhang, Q.; Huang, J.-Q.; Qian, W.-Z.; Zhang, Y.-Y.; Wei, F. The road for nanomaterials industry: A review of carbon nanotube production, post-treatment, and bulk applications for composites and energy storage, Small, 2013, 9, 1237-1265

[10] Hou, G.; Su, R.; Wang, A.; Ng, V.; Li, W.; Song, Y.; Zhang, L.; Sundaram, M.; Shanov, V.; Mast, D. The effect of a convection vortex on sock formation in the floating catalyst method for carbon nanotube synthesis. Carbon 2016, 102, 513-519.

[11] Mikhalchan, A.; Fan, Z.; Tran, T. Q.; Liu, P.; Tan, V. B. C.; Tay, T.-E.; Duong, H. M. Continuous and scalable fabrication and multifunctional properties of carbon nanotube aerogels from the floating catalyst method. Carbon 2016, 102, 409-418.

[12] Barreiro, A.; Hampel, S.; Rümmeli, M. H.; Kramberger, C.; Grüneis, A.; Biedermann, K.; Leonhardt, A.; Gemming, T.; Büchner, B.; Bachtold, A. Thermal decomposition of ferrocene as a method for production of single-walled carbon nanotubes without additional carbon sources. J. Phys. Chem. B 2006, 110, 20973-20977.

[13] Flahaut, E.; Govindaraj, A.; Peigney, A.; Laurent, C.; Rousset, A.; Rao, C. N. R. Synthesis of singlewalled carbon nanotubes using binary ( $\mathrm{Fe}, \mathrm{Co}, \mathrm{Ni}$ ) alloy nanoparticles prepared in situ by the reduction of oxide solid solutions. Chem. Phys. Lett. 1999, 300, 236- 242.

[14] Bower, C.; Zhou, O.; Zhu, W.; Werder, D. J.; Jin, S. Nucleation and growth of carbon nanotubes by microwave plasma chemical vapor deposition. Appl. Phys. Lett. 2000, 77, 2767-2769.

[15] Cheng, H. M.; Li, F.; Su, G.; Pan, H. Y.; He, L. L.; Sun, X.; Dresselhaus, M. S. Large-scale and low-cost synthesis of single-walled carbon nanotubes by the catalytic pyrolysis of hydrocarbons. Appl. Phys. Lett. 1998, 72, 3282-3284.

[16] Andrews, R.; Jacques, D.; Rao, A. M.; Derbyshire, F.; Qian, D.; Fan, X.; Dickey, E. C.; Chen, J. Continuous production of aligned carbon nanotubes: a step closer to commercial realization. Chem. Phys. Lett. 1999, 303, 467-474.

[17] Nasibulin, A. G.; Pikhitsa, P. V.; Jiang, H.; Kauppinen, E. I. Correlation between catalyst particle and single-walled carbon nanotube diameters. Carbon 2005, 43, 2251-2257.

[18] Li, Y.; Kim, W.; Zhang, Y.; Rolandi, M.; Wang, D.; Dai, H. Growth of single-walled carbon nanotubes from discrete catalytic nanoparticles of various sizes. J. Phys. Chem. B 2001, 105, 11424-11431.

[19] Lee, C.-H.; Lee, J.; Yeo, S.; Lee, S.-H.; Kim, T.; Cha, H.-G.; Eun, Y.; Park, H. J.; Kim, S. M.; Lee, K.-H. Evolution of implanted Fe ions in $\mathrm{SiO} 2 / \mathrm{Si}$ wafer into uniformly sized catalyst particles for carbon nanotube forest growth. Carbon 2017, 123, 122-128.

[20] Yu, F.; Yang, M.; Li, F.; Su, C.; Ma, B.; Yuan, Z.; Chen, J.; Ma, J. The growth mechanism of single-walled carbon nanotubes with a controlled diameter. Phys. E 2012, 44, 2032-2040.

[21] Nessim, G. D.; Hart, A. J.; Kim, J. S.; Acquaviva, D.; Oh, J.; Morgan, C. D.; Seita, M.; Leib, J. S.; Thompson, C. V. Tuning of vertically-aligned carbon nanotube diameter and areal density through catalyst pre-treatment. Nano Lett. 2008, 8, 3587-3593.

[22] Mazzucco, S.; Wang, Y.; Tanase, M.; Picher, M.; Li, K.; Wu, Z.; Irle, S.; Sharma, R. Direct evidence of active and inactive phases of Fe catalyst nanoparticles for carbon nanotube formation. J. Catal. 2014, 319, 54-60.

[23] Wirth, C. T.; Bayer, B. C.; Gamalski, A. D.; Esconjauregui, S.; Weatherup, R. S.; Ducati, C.; Baehtz, C.; Robertson, J.; Hofmann, S.he phase of iron catalyst nanoparticles during carbon nanotube growth. Chem. Mater. 2012, 24, 4633-4640.

[24] Heresanu, V.; Castro, C.; Cambedouzou, J.; Pinault, M.; Stephan, O.; Reynaud, C.; Mayne-L'Hermite, M.; Launois, P. Nature of the catalyst particles in CCVD synthesis of multiwalled carbon nanotubes revealed by the cooling step study. J. Phys. Chem. C 2008, 112, 7371-7378.

[25] Pinault, M.; Mayne-L'Hermite, M.; Reynaud, C.; Pichot, V.; Launois, P.; Ballutaud, D. Growth of multiwalled carbon nanotubes during the initial stages of aerosol-assisted CCVD. Carbon 2005, 43, 2968-2976.

[26] Moisala, A.; Nasibulin, A. G.; Kauppinen, E. I. The role of metal nanoparticles in the catalytic production of single-walled carbon nanotubes - a review. J. Phys.: Condens. Matter 2003, 15, S3011. 
[27] Castro, C.; Pinault, M.; Coste-Leconte, S.; Porterat, D.; Bendiab, N.; Reynaud, C.; Mayne-L'Hermite, M. Dynamics of catalyst particle formation and multi-walled carbon nanotube growth in aerosol-assisted catalytic chemical vapor deposition. Carbon 2010, 48, 3807-3816.

[28] Zhang, Q.; Huang, J.-Q.; Zhao, M.-Q.; Qian, W.-Z.; Wei, F. Modulating the diameter of carbon nanotubes in array form via floating catalyst chemical vapor deposition. Appl. Phys. A: Mater. Sci. Process. 2009, 94, 853-860.

[29] Castro, C.; Pinault, M.; Porterat, D.; Reynaud, C.; Mayne- L'Hermite, M. The role of hydrogen in the aerosol-assisted chemical vapor deposition process in producing thin and densely packed vertically aligned carbon nanotubes. Carbon 2013, 61, 585-594.

[30] Kuwana, K.; Saito, K. Modeling ferrocene reactions and iron nanoparticle formation: Application to CVD synthesis of carbon nanotubes. Proc. Combust. Inst. 2007, 31, 1857-1864.

[31] Conroy, D.; Moisala, A.; Cardoso, S.; Windle, A.; Davidson, J. Carbon nanotube reactor: Ferrocene decomposition, iron particle growth, nanotube aggregation and scale-up. Chem. Eng. Sci. 2010, 65, 2965-2977.

[32] Futko, S.; Shulitskii, B. G.; Labunov, V. A.; Ermolaeva, E. M. Simulation of the kinetics of growth of iron nanoparticles in the process of chemical vapor deposition of hydrocarbons with injection of ferrocene for the synthesis of carbon-nanotube arrays. J. Eng. Phys. Thermophys. 2015, 88, 1432-1441.

[33] He, D.; Li, H.; Bai, J. Experimental and numerical investigation of the position-dependent growth of carbon nanotube-alumina microparticle hybrid structures in a horizontal CVD reactor. Carbon 2011, 49, 5359-5372.

[34] Ma, Y.; Dichiara, A. B.; He, D.; Zimmer, L.; Bai, J. Control of product nature and morphology by adjusting the hydrogen content in a continuous chemical vapor deposition process for carbon nanotube synthesis. Carbon 2016, 107, 171-179.

[35] He, D.; Bai, J. Acetylene-Enhanced Growth of Carbon Nanotubes on Ceramic Microparticles for MultiScale Hybrid Structures. Chem. Vap. Deposition 2011, 17, 98-106.

[36] Satishkumar, B. C.; Govindaraj, A.; Sen, R.; Rao, C. N. R. Single- walled nanotubes by the pyrolysis of acetylene-organometallic mixtures. Chem. Phys. Lett. 1998, 293, 47-52.

[37] Xiang, R.; Einarsson, E.; Okawa, J.; Miyauchi, Y.; Maruyama, S. Acetylene-accelerated alcohol catalytic chemical vapor deposition growth of vertically aligned single-walled carbon nanotubes. J. Phys. Chem. C 2009, 113, 7511-7515.

[38] Eremin, A. V.; Gurentsov, E. V.; Musikhin, S. A. Temperature influence on the properties of carbonencapsulated iron nanoparticles forming in pyrolysis of gaseous precursors. J. Alloys Compd. 2017, 727, $711-720$

[39] Kaito, C. Coalescence growth of smoke particles prepared by a gas-evaporation technique. Jpn. J. Appl. Phys. 1978, 17, 601.

[40] Heist, R. H.; Ahmed, J.; Janjua, M. Effects of background gases on the homogeneous nucleation of vapors. 2. J. Phys. Chem. 1995, 99, 375-383.

[41] Braun, S.; Römer, F.; Kraska, T. Influence of the carrier gas molar mass on the particle formation in a vapor phase. J. Chem. Phys. 2009, 131, 064308.

[42] Mehedi,H.-a.;Arnault,J.-C.;Eon,D.;Hébert,C.;Carole,D.; Omnes, F.; Gheeraert, E. Etching mechanism of diamond by Ni nanoparticles for fabrication of nanopores. Carbon 2013, 59, 448-456.

[43] Dresselhaus, M. S.; Jorio, A.; Saito, R. Characterizing graphene, graphite, and carbon nanotubes by Raman spectroscopy. Annu. Rev. Condens. Matter Phys. 2010, 1, 89-108.

[44] Zhang, H.; Cao, G.; Wang, Z.; Yang, Y.; Shi, Z.; Gu, Z. Influence of ethylene and hydrogen flow rates on the wall number, crystallinity, and length of millimeter-long carbon nanotube array. J. Phys. Chem. C 2008, 112, 12706-12709.

[45] Zhao, X.; Liu, Y.; Cui, R.; Li, Y. Nucleation of copper nanoparticles on quartz as catalysts to grow single-walled carbon nanotube arrays. Carbon 2016, 110, 390-395. 
[46] Lu, C.; Liu, J. Controlling the diameter of carbon nanotubes in chemical vapor deposition method by carbon feeding. J. Phys. Chem. B 2006, 110, 20254-20257.

[47] Elliott, B. R.; Host, J. J.; Dravid, V. P.; Teng, M. H.; Hwang, J.- H. A descriptive model linking possible formation mechanisms for graphite-encapsulated nanocrystals to processing parameters. J. Mater. Res. 1997, 12, 3328-3344.

[48] Khavrus, V. O.; Ibrahim, E. M. M.; Leonhardt, A.; Hampel, S.; Oswald,S.; Täschner,C.; Büchner,B. Conditions of simultaneous growth and separation of single-and multiwalled carbon nanotubes. J. Phys. Chem. C 2009, 114, 843-848.

[49] Chen, H.; Chen, M.; Zhang, Y.; Li, Q. Rational control on floating catalysts for the growth of carbon nanotube assemblies: From vertically aligned carbon nanotube arrays to carbon nanotube films. Appl. Surf. Sci. 2015, 353, 651-661.
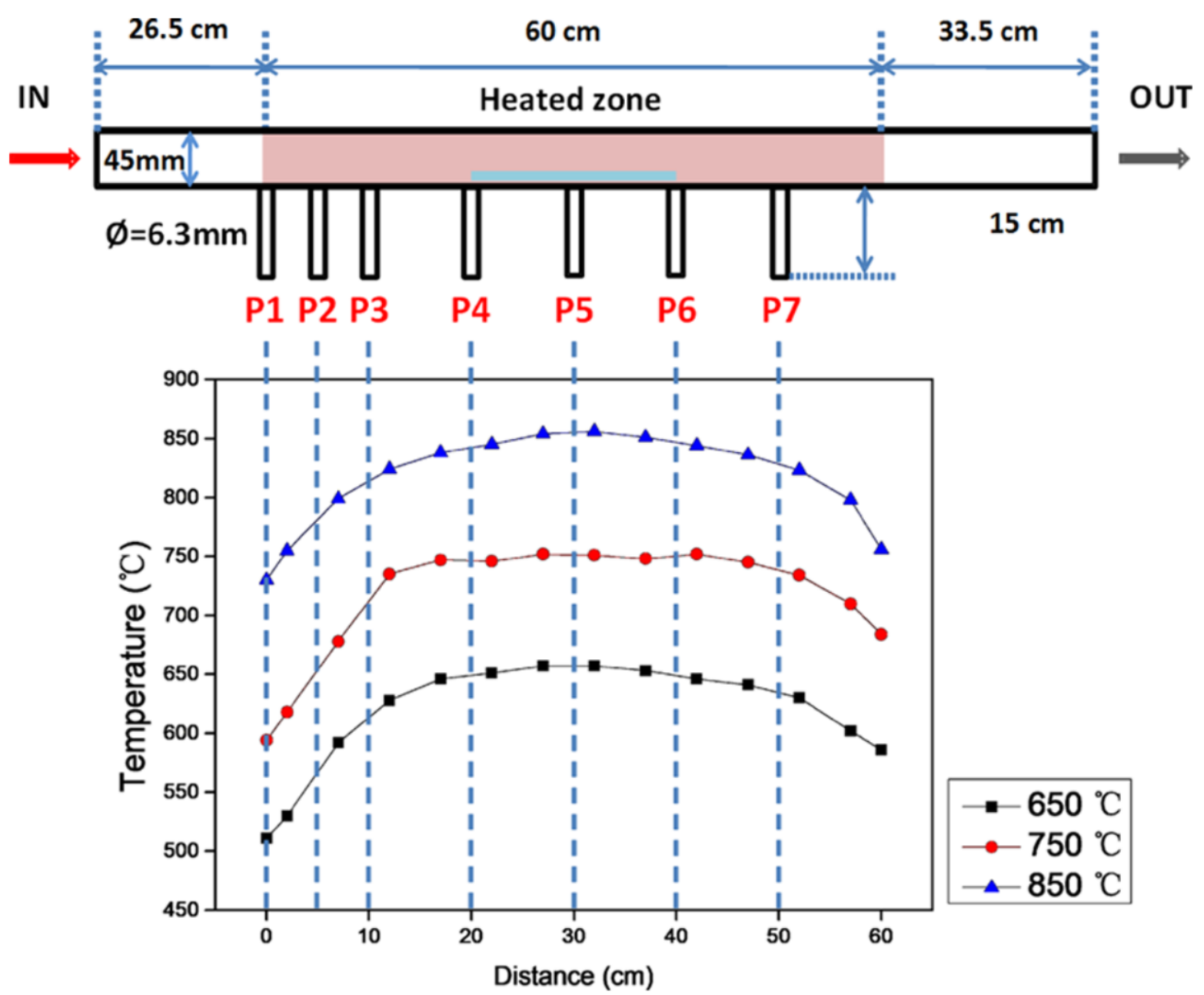

Figure 1: Schematics of the stainless steel CVD reactor with seven small open-ended tubes at different positions labeled $\mathrm{P} 1, \mathrm{P} 2, \mathrm{P} 3, \mathrm{P} 4, \mathrm{P} 5, \mathrm{P} 6$, and $\mathrm{P} 7$ along the reactor. 

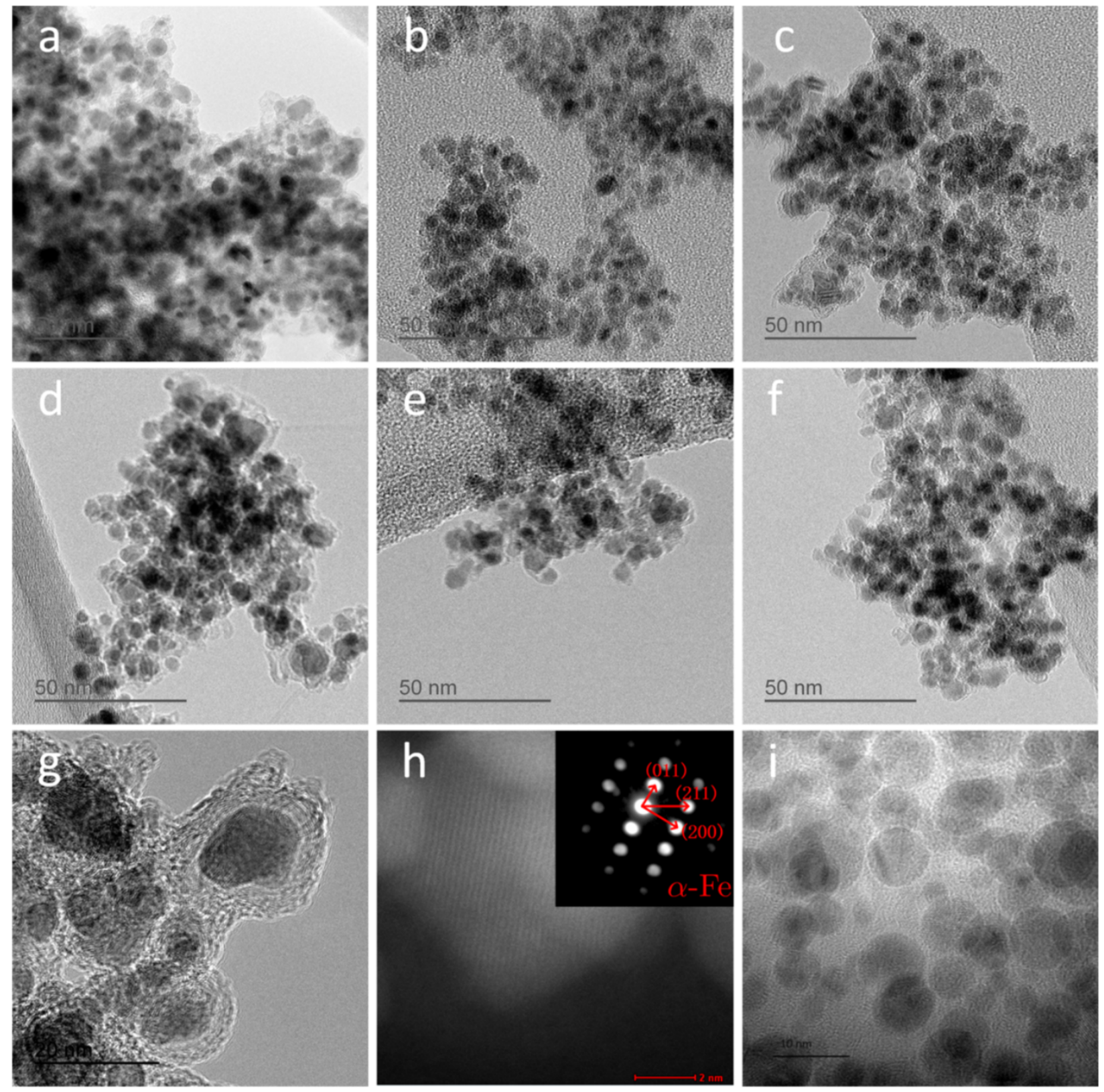

Figure 2: Typical TEM images of NPs obtained in the gas phase at different positions (a) P2, (b) P3, (c) P4, (d) P5, (e) P6, and (f) P7. (g) HRTEM image of NPs at P5. (h) Scanning TEM image shows the lattice fringes of the iron core of NPs at P5. (Selected-area EDP in the iron core region is shown in the inset.) (i) NPs without obvious carbon shell around the iron core are found at the front of the reactor (P3). 

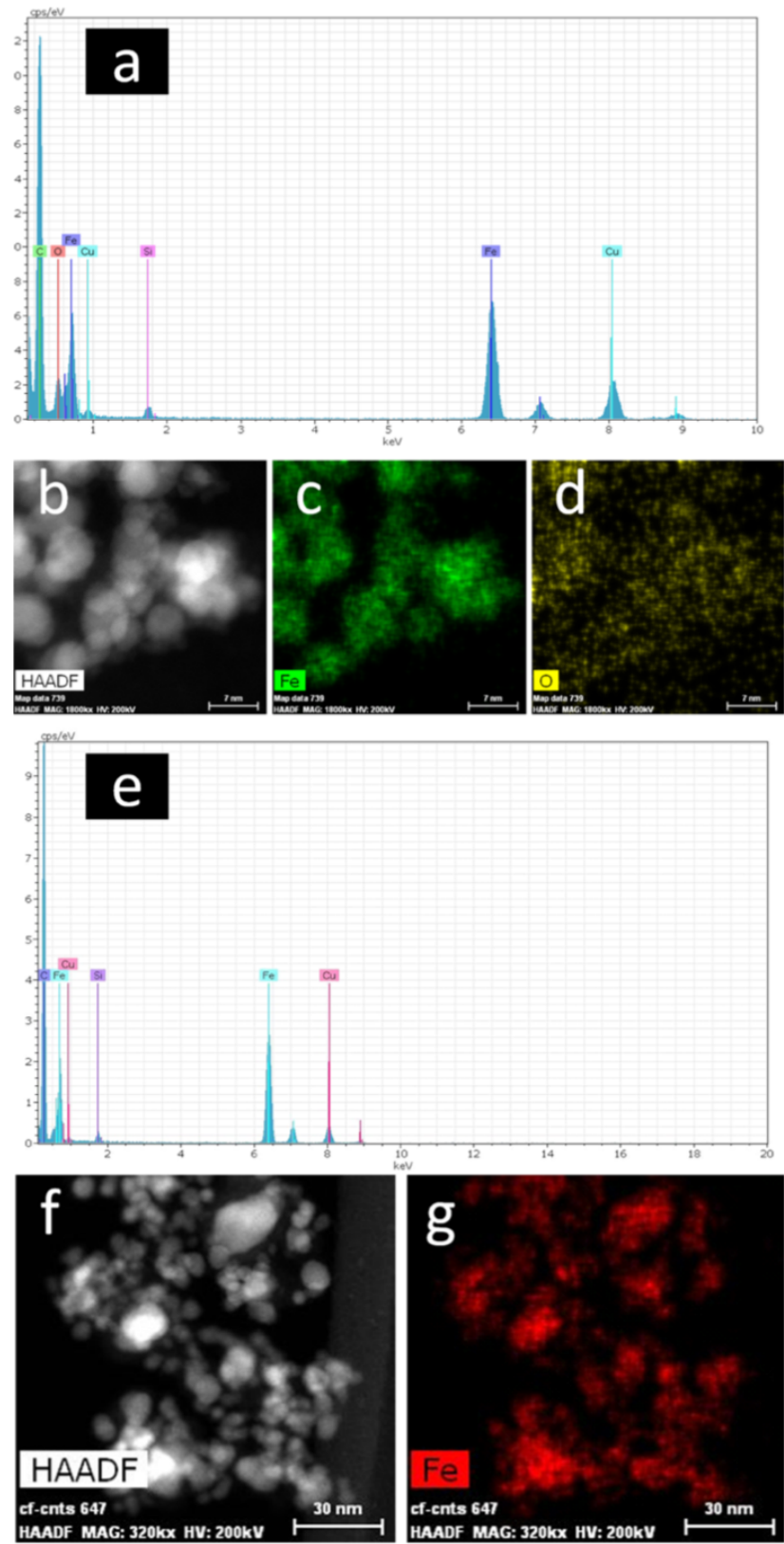

Figure 3: Spectrum (a) and map distribution (b-d) of chemical elements in the sample of NPs obtained at the front of the reactor (P3). The spectrum (e) and map distribution (f,g) of chemical elements in the sample of NPs obtained in the center of the heated zone (P5). 

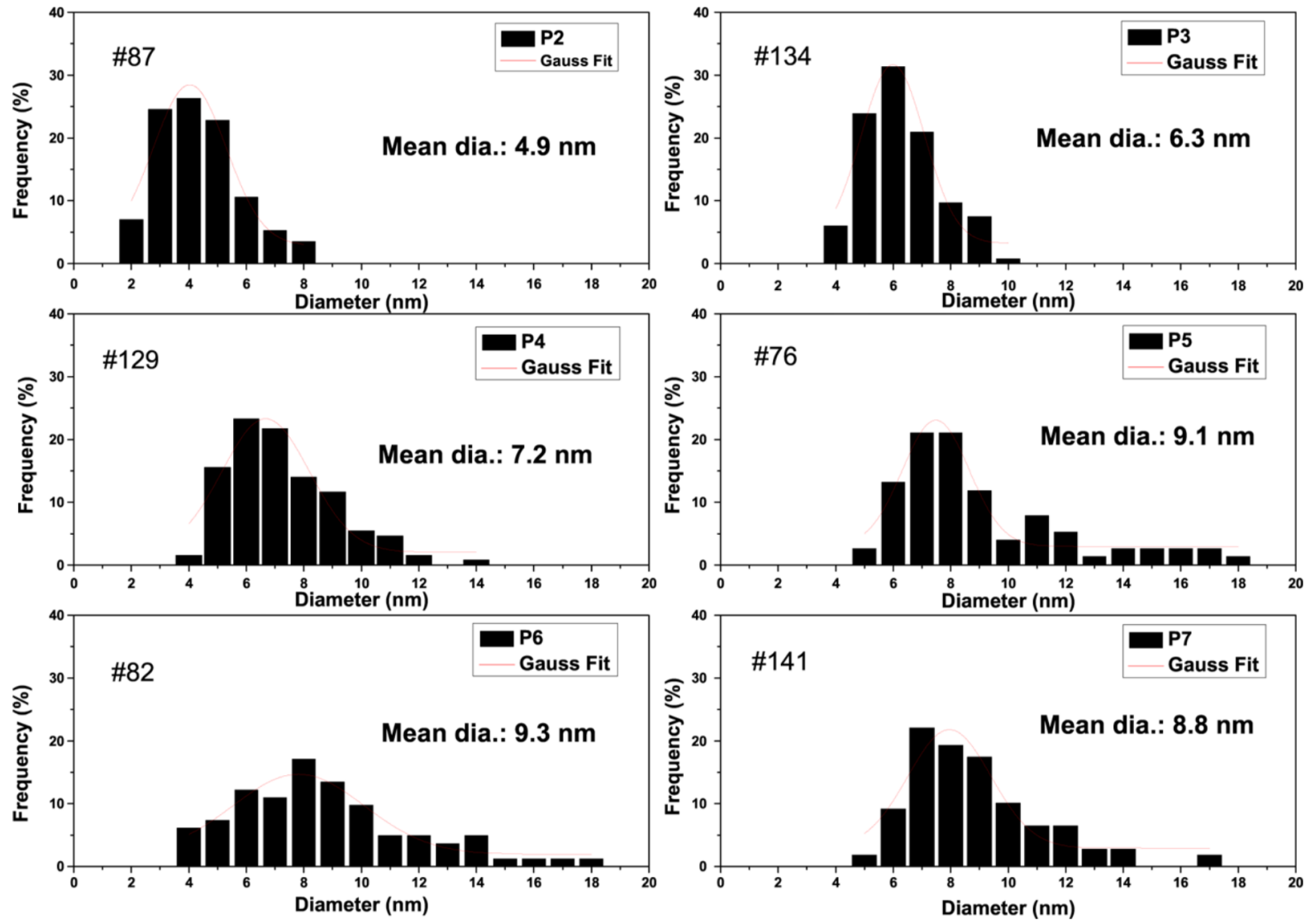

Figure 4: NP size evolutionin the gas phase at different positions in the CVD reactor at $850^{\circ} \mathrm{C}$. 

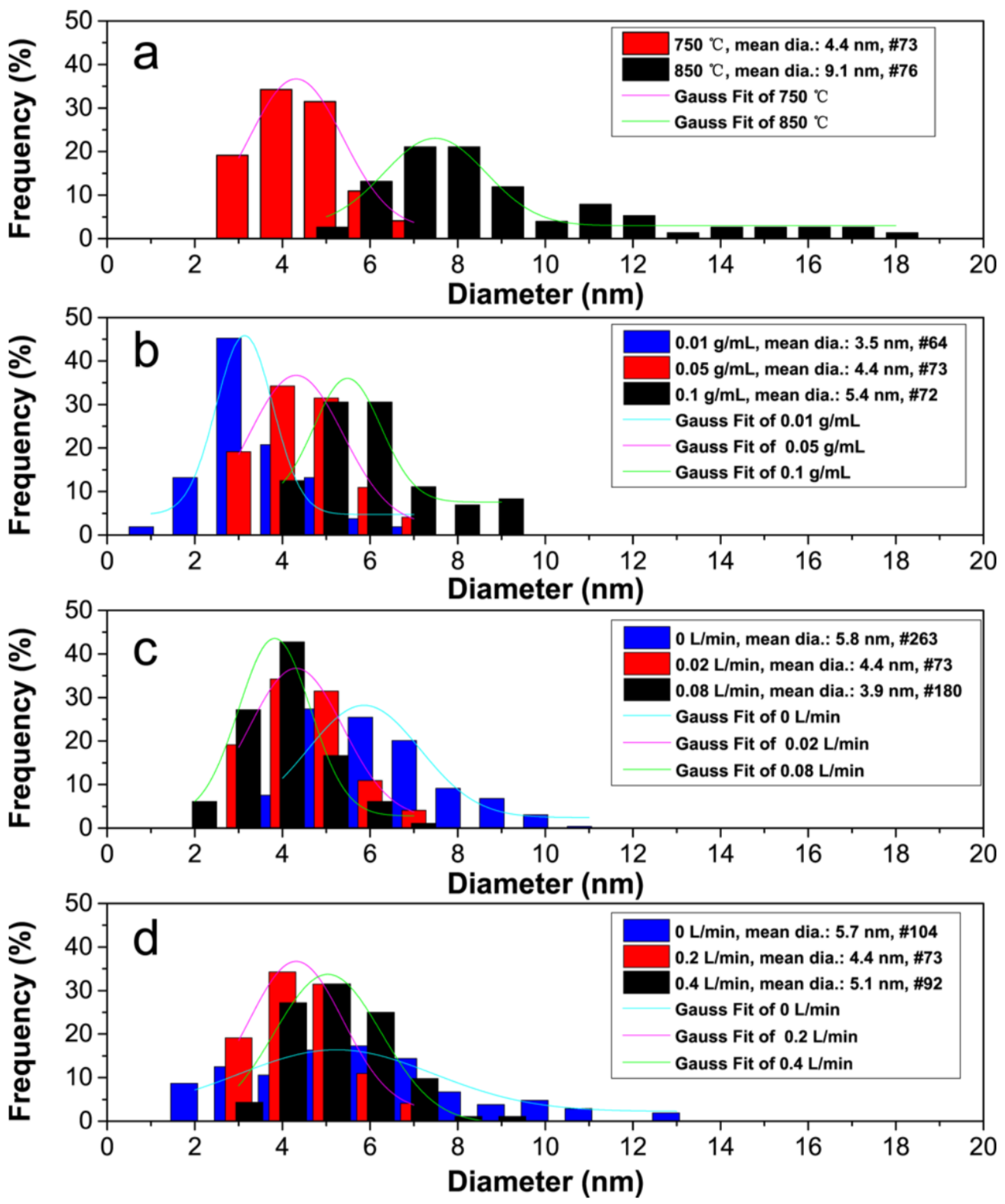

Figure 5: NP size distribution in the gas phase at the center of the heated zone in the CVD reactor (P5) at (a) different temperatures, (b) different ferrocene/xylene concentrations, (c) different $\mathrm{C}_{2} \mathrm{H}_{2}$ gas flows, and (d) different $\mathrm{H}_{2}$ gas flows. 

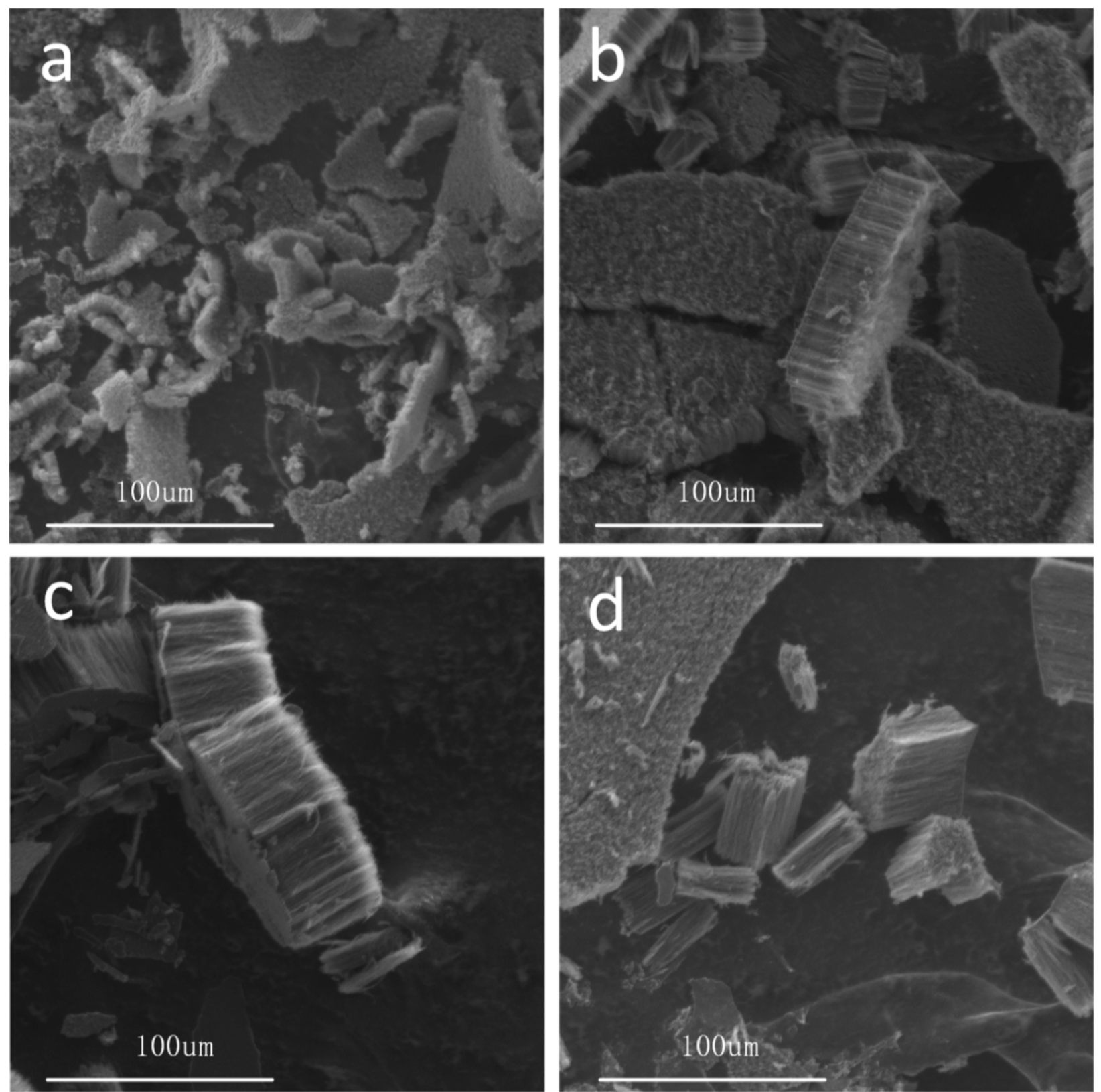

Figure 6: SEM images of the CNT growth on the quartz plate in the reactor at different axial locations (a) P1, (b) P2, (c) P3, and (d) P4.
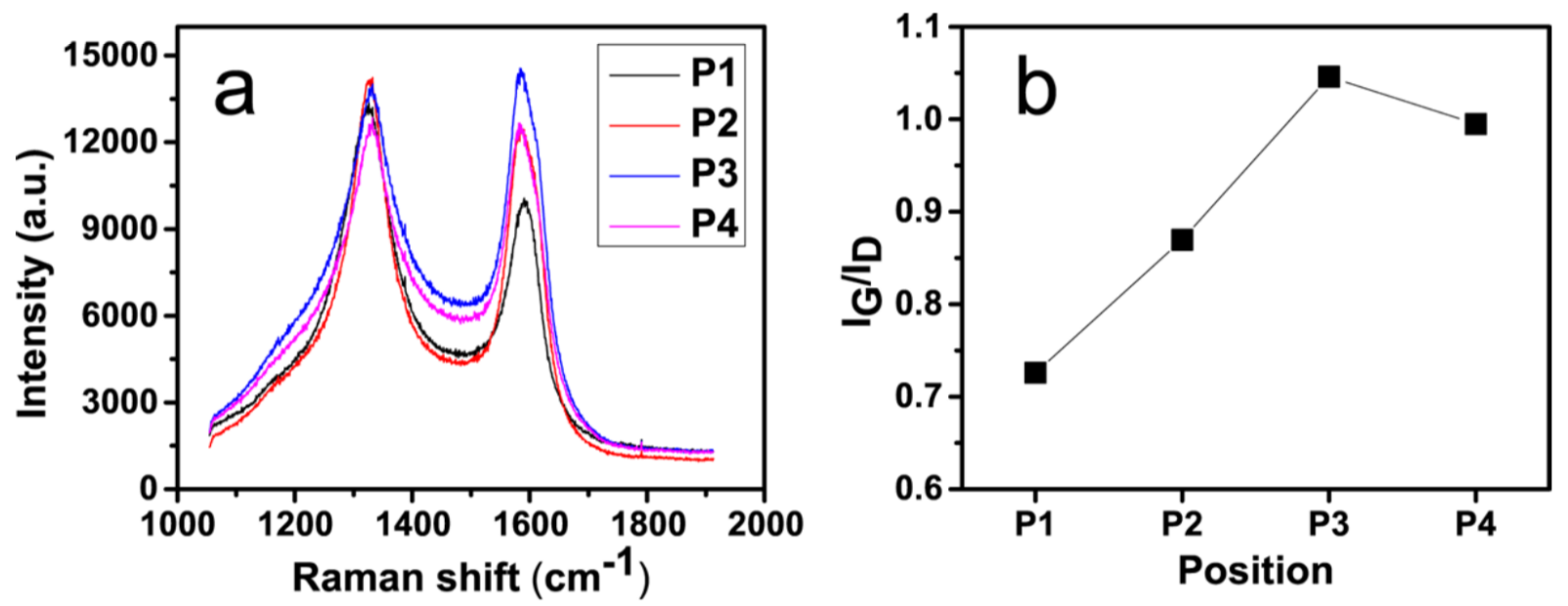

Figure 7: (a) Raman spectra and (b) corresponding intensity ratio between D-band and G-band (IG/ID) of the CNT growth on the quartz plate in the reactor at different axial locations (from P1 to P4). 


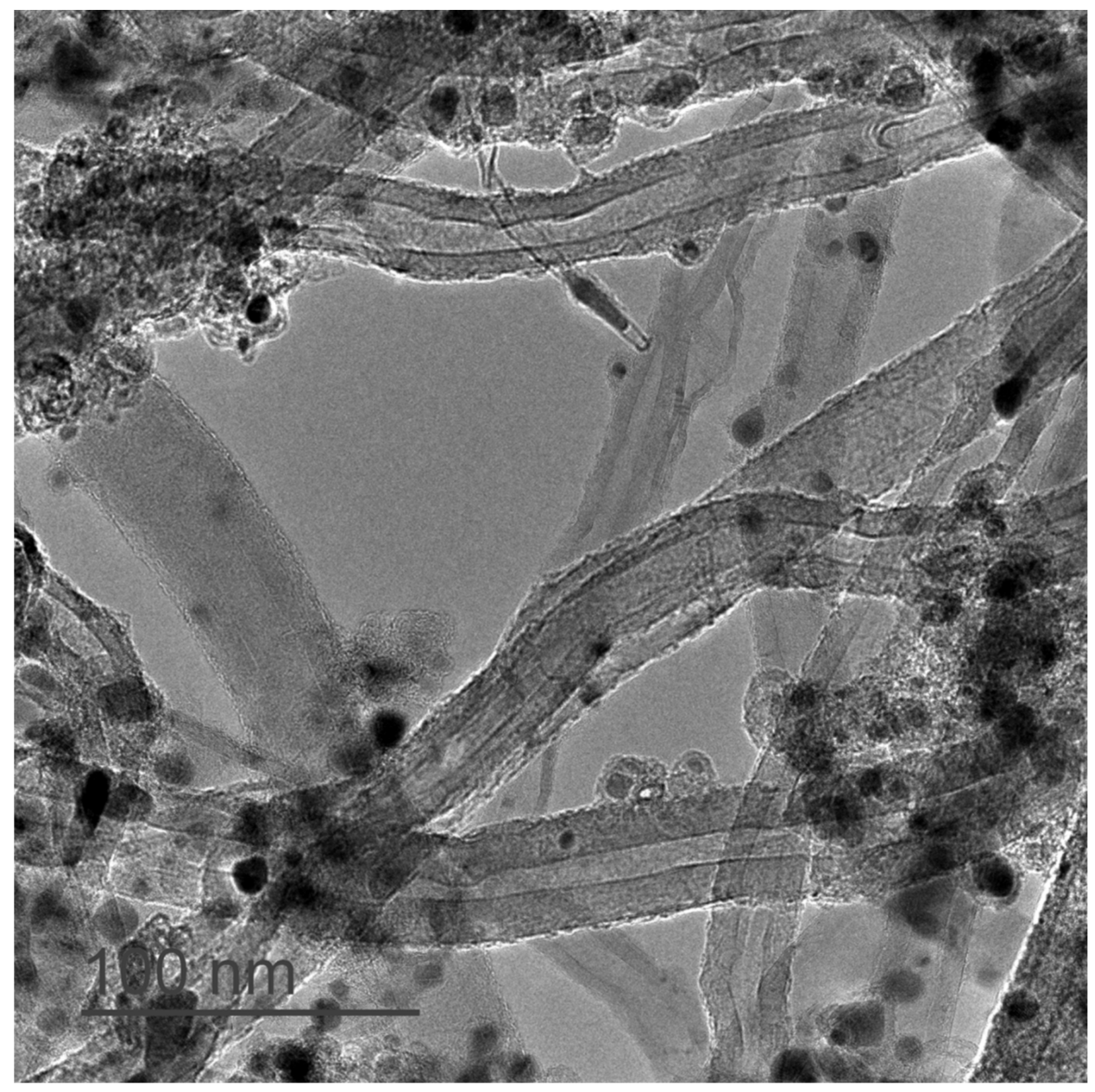

Figure 8: TEM image of the CNT growth on the quartz plate at the front of the reactor (P3). 

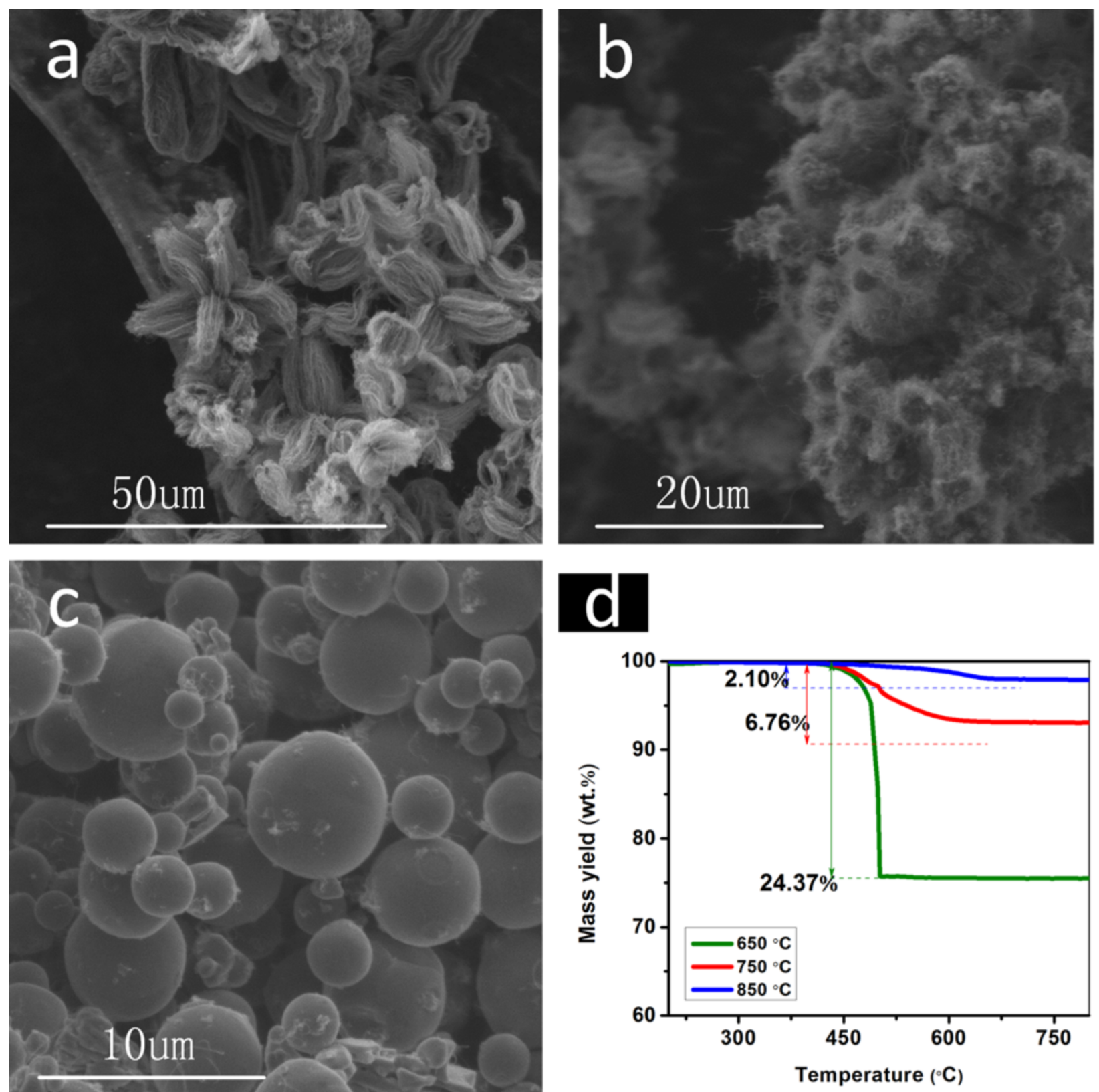

Figure 9: SEM images of the CNT growth on $\mu-\mathrm{Al}_{2} \mathrm{O}_{3}$ at the center of the heated zone (P5) at (a) 650, (b) 750 , and (c) $850^{\circ} \mathrm{C}$. (d) TGA curves of CNTs synthesized on $\mu-\mathrm{Al}_{2} \mathrm{O}_{3}$ at different temperatures. 


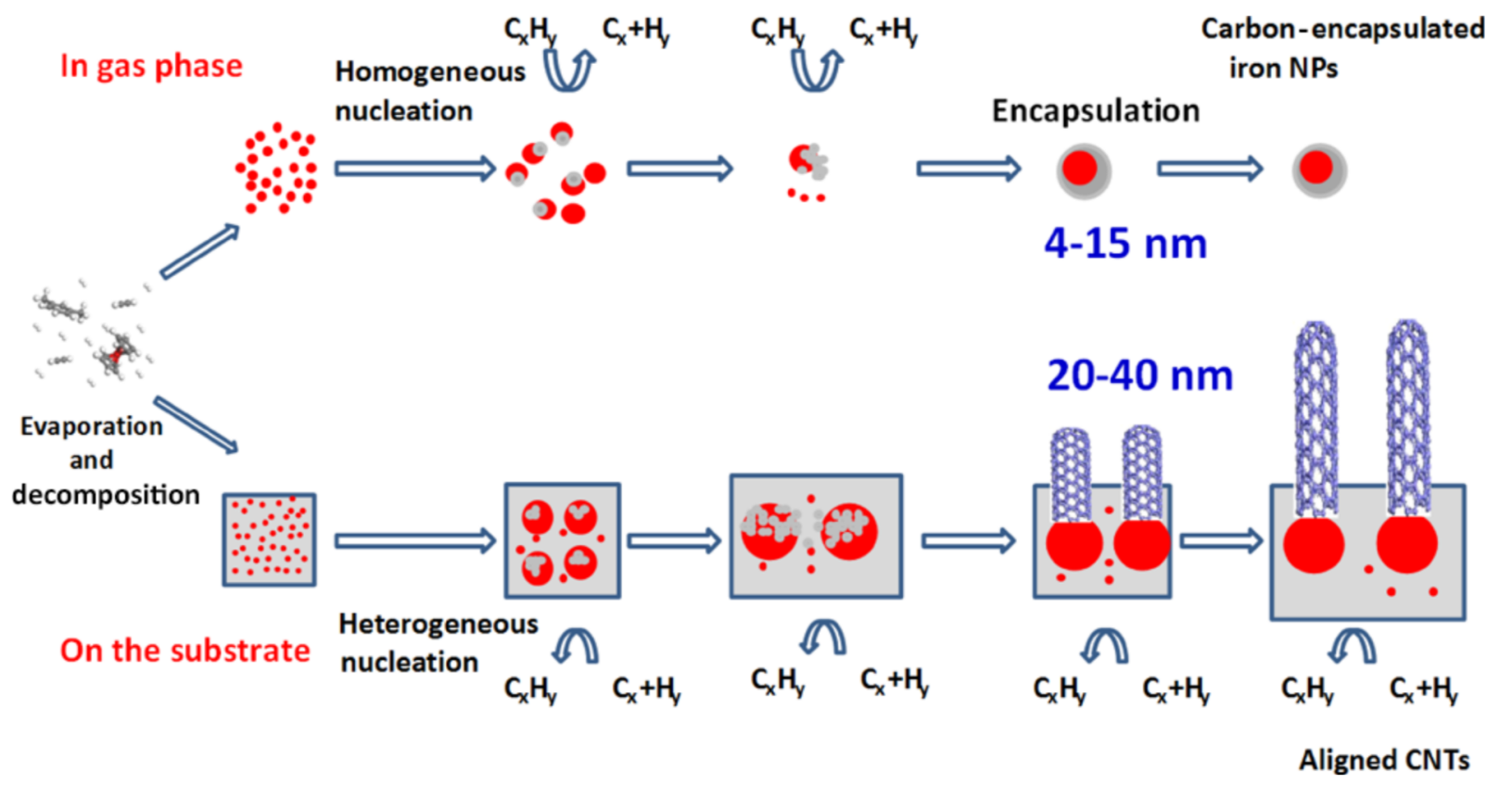

Figure 10: Proposed models for the NP formation in the gas phase and on the substrate under FCCVD condition. 